\title{
O Assistente Social enquanto trabalhador assalariado: desafios presentes no cotidiano ${ }^{1}$
}

\author{
El Asistente Social como trabajador asalariado: desafíos presentes en el \\ cotidiano
}
The Social Worker as a salaried worker: challenges present in everyday life

\author{
Maria Eliete dos Santos² \\ Maria Lourdes Lopes ${ }^{3}$
}

\begin{abstract}
Resumo
Objetivando refletir sobre a condição do assistente social enquanto trabalhador assalariado e os desafios presentes no cotidiano profissional frente a atual conjuntura capitalista busca-se por meio da pesquisa bibliográfica, debater sobre as transformações políticas, econômicas e sociais que vem ocorrendo nas últimas décadas e que tem impactado diretamente no mundo do trabalho e no cotidiano do exercício profissional do assistente social, partindo da premissa do reconhecimento do Assistente Social enquanto trabalhador assalariado, inserido no atual sistema capitalista vigente, busca-se com a realização do presente trabalho contribuir para o debate crítico da categoria a cerca dos desafios postos a profissão frente às condições de trabalho precarizado do assistente social na atual conjuntura capitalista.
\end{abstract}

Palavras-chaves: Assistente Social; direitos sociais; capitalismo; trabalho.

\section{Resumen}

El objetivo de reflexionar sobre la condición del asistente social como trabajador asalariado y los desafíos presentes en el cotidiano profesional frente a la actual coyuntura capitalista se busca por medio de la investigación bibliográfica, debatir sobre las transformaciones políticas, económicas y sociales que vienen ocurriendo en las últimas décadas y que tiene que afectó directamente al mundo del trabajo y en el cotidiano del ejercicio profesional del asistente social, partiendo de la premisa del reconocimiento del Asistente Social como trabajador asalariado, inserto en el actual sistema capitalista vigente, se busca con la realización del presente trabajo contribuir al debate crítico de la acción categoría a cerca de los desafíos puestos a la profesión frente a las condiciones de trabajo precargado del asistente social en la actual coyuntura capitalista.

Palabras clave: Asistente Social; derechos sociales; capitalismo; trabajo.

Abstract

\footnotetext{
1 Artigo elaborado como trabalho de conclusão de curso da Especialização em Serviço Social na Contemporaneidade, sob a orientação da professora Dra. Adriéli Volpato Craveiro.

${ }^{2}$ Especialista em Serviço Social na Contemporaneidade e graduada em Gestão Pública; Assistente Social da Prefeitura Municipal de Foz do Iguaçu; Foz do Iguaçu, Paraná, Brasil; eliete_a.s@ hotmail.com.

${ }^{3}$ Especialista em Serviço Social na Contemporaneidade e graduada em Serviço Social; Assistente Social do Conselho Comunitário da Vila C; Foz do Iguaçu, Paraná, Brasil; foz_lourdes@ hotmail.com.
} 
Aiming to reflect on the condition of the social worker as a salaried worker and the challenges present in the professional daily life in the face of the current capitalist conjuncture is sought through the bibliographical research, debate on the political, economic and social transformations that have been occurring in the last decades and that has directly impacted in the world of work and in the day-to-day work of the social worker, starting from the premise of the recognition of the Social Worker as a salaried worker, inserted in the current capitalist system, seeks to contribute to the critical debate of the category about the challenges faced by the profession in the precarious working conditions of the social worker in the current capitalist conjuncture.

Keywords: Social Worker; social rights; capitalism; job.

\section{INTRODUÇÃO}

O presente estudo tem por objetivo refletir sobre o assistente social enquanto trabalhador assalariado e os desafios presentes no cotidiano profissional, tal reflexão é fundamental devido às condições de trabalho do assistente social contemporaneamente.

Assim, visa-se debater sobre as transformações políticas, econômicas e sociais que vem ocorrendo nas últimas décadas e que tem impactado diretamente no mundo do trabalho e no cotidiano do exercício profissional do assistente social, partindo da premissa do reconhecimento do assistente social enquanto trabalhador assalariado, inserido no sistema capitalista vigente.

Deste modo, a partir do debate crítico, o estudo visa contribuir para a reflexão da categoria do Serviço Social sobre as ações, as mediações e lutas em prol da classe trabalhadora, alijando os seus interesses enquanto pertencente a esta mesma classe explorada, as condições de trabalho do assistente social diante do atual cenário político e econômico, as quais são compreendidas como possibilidades de reflexão e ação coletiva diante da retirada de direitos, o que reflete diretamente na atuação profissional.

O que motivou a escolha do tema foram as inquietações provocadas diante das profundas mudanças que vem ocorrendo no cenário político e econômico nas últimas décadas, despertando assim a curiosidade de aprofundar o conhecimento sobre as condições de trabalho do assistente social diante da realidade atual, tornando tão intricadas e contraditórias as relações de trabalho e a efetivação de direitos, considerando que o trabalho no sistema capitalista, limita a possibilidade do trabalhador explorar suas potencialidades e autonomia, ficando submetidos ao sistema vigente.

A pesquisa se baseia na metodologia da pesquisa bibliográfica, visto que a mesma será feita principalmente em livros, artigos científicos, revistas eletrônicas que já abordaram o tema de alguma forma e que eventualmente, auxiliarão a fundamentação teórica do estudo a ser realizado a fim de alcançar o objetivo proposto. De acordo com Gil $(2009$, p. 45) "a principal vantagem da pesquisa bibliográfica reside no fato de permitir ao investigador a cobertura de 
uma gama de fenômenos muito mais ampla do que aquela que poderia pesquisar diretamente". Desta forma, os autores optaram por aplicar neste trabalho o foco em pesquisas bibliográficas, que junto com materiais de campo já adquiridos na experiência e histórico laboral dos autores na área, vai ser complementado com as teorias pesquisadas.

Frente ao exposto, no primeiro tópico discutiremos o trabalho na sociedade capitalista, as transformações que vem ocorrendo nas últimas décadas no mundo do trabalho em decorrência das exigências do mundo capitalista. No segundo tópico iremos discorrer sobre o assistente social enquanto trabalhador assalariado, perpassando pela discussão de processo de trabalho, força de trabalho, instrumento de trabalho, a relativa autonomia profissional. No terceiro tópico abordaremos os desafios presentes no cotidiano profissional do assistente social frente ao atual cenário político brasileiro. Por fim, apresentaremos as considerações finais.

\section{O TRABALHO NA SOCIEDADE CAPITALISTA}

De acordo com Marx (2013) podemos compreender o trabalho como categoria fundante do ser social, é a relação direta de interação do homem com a natureza que possibilita a manutenção da existência e sobrevivência humana, sendo por meio do trabalho que ocorre a transformação da natureza, do homem, e consequentemente a transformação das relações sociais, uma vez que ao trabalhar os homens estabelecem relações entre si, ou seja, relações sociais.

Como assinala Marx (2013, p. 326-327):

O trabalho é antes de tudo, um processo entre o homem e a natureza, processo este em que o homem, por sua própria ação, medeia, regula e controla seu metabolismo com a natureza. Ele se confronta com a matéria natural como com uma potência natural [Naturmacht]. A fim de se apropriar da matéria natural de uma forma útil para sua própria vida, ele põe em movimento as forças naturais pertencentes a sua corporeidade: seus braços e pernas, cabeça e mãos. Agindo sobre a natureza externa e modificando-a por meio desse movimento, ele modifica, ao mesmo tempo, sua própria natureza. Ele desenvolve as potências que nela jazem latentes e submete o jogo de suas forças a seu próprio domínio. Não se trata, aqui, das primeiras formas instintivas, animalescas [tierartig], do trabalho. Um incomensurável intervalo de tempo separa o estágio em que o trabalhador se apresenta no mercado como vendedor de sua própria força de trabalho daquele em que o trabalho humano ainda não se desvencilhou de sua forma instintiva. Pressupomos o trabalho numa forma em que ele diz respeito unicamente ao homem. Uma aranha executa operações semelhantes às do tecelão, e uma abelha envergonha muitos arquitetos com a estrutura de sua colmeia. Porém, o que desde o início distingue o pior arquiteto da melhor abelha é o fato de que o primeiro tem a colmeia em sua mente antes de construí-la com a cera. No final do processo de trabalho, chega-se a um resultado que já estava presente na representação do trabalhador no início do processo, portanto, um resultado que já existia idealmente. 
O homem possui capacidade prévia de ideação, assim, ao agir sobre a natureza e produzir a transformação desta, ocorre em sua consciência uma projeção ideal do objetivo que quer alcançar, capacidade teleológica. Essa forma de transformar a natureza é iminentemente particularidade do homem, é esta capacidade que o diferencia dos animais. Assim, é possível compreender que é pela consciência que o trabalho se consiste.

Ao verificarmos a trajetória histórica do trabalho notamos que a primeira manifestação do trabalho se dá por via das mãos enquanto instrumento de trabalho, o homem transformava a natureza a fim de satisfazer suas necessidades básicas, no entanto segundo Passos (2016) ao longo do processo histórico do homem e das relações sociais, novas necessidades foram surgindo para a existência humana, também foram surgindo novas e diversas capacidades que possibilitaram que os sujeitos escolhessem novos processos manifestos na sua força de trabalho e ainda em seus instrumentos de trabalho.

Essas determinações, conforme pontua Passos (2006) implicam sobre as relações sociais. Há um entrelaçamento entre as relações sociais e o comportamento determinado pelas condições materiais que resultam em formas de ser determinadas, que condicionam os indivíduos, seus comportamentos, representações e ideias, a partir do desenvolvimento das forças produtivas e por seu intercâmbio. Portanto, a consciência é moldada e determinada de acordo com a realidade vivenciada pelo ser social.

De acordo com Marx (2016) a mercadoria produzida pelo ser humano que inicialmente era utilizada para o consumo e satisfação das necessidades humanas, no sistema capitalista passa a ter valor de troca e venda, quem produz a mercadoria direciona seu trabalho para satisfazer as necessidades ou as conveniências de terceiros, o objeto é destinado ao individuo a quem possa ser útil, em troca de outro objeto, assim, essa ação se converte em mercadoria. A troca de mercadorias de espécies diferentes estabelece o seu valor de troca. Posteriormente, a mercadoria passa a ter forma de valor, sendo o ouro utilizado a principio como forma de troca, no entanto ganhou medida de valor, pois as trocas eram feitas exclusivamente produtos/ouro, adquirindo forma monetária. É nesse processo que se tem assentado a alienação, a desumanização e a desigualdade social, que resultam no enriquecimento e na satisfação de poucos em detrimento das reais necessidades sociais da grande maioria. Sobre o processo de alienação (IAMAMOTO, 2000, p. 55-56) afirma que:

Portanto, a relação entre o trabalhador e o produto de seu trabalho é uma relação entre o produtor e um objeto alheio, dotado da condição de exercer poder sobre ele. A objetivação do trabalho, desta substância criadora de riqueza, no produto, torna-se para o produtor escravização de si mesmo aos objetos criados pelo seu trabalho. Mas a alienação do trabalhador não só se expressa na sua relação com os produtos de 
trabalho. A alienação se manifesta no próprio ato da produção, no trabalho. O trabalho aparece como algo externo ao trabalhador, como algo que não se afirma, mas se nega a si mesmo; que o mortifica. Só se sente livre quando deixa de trabalhar.

Desta forma, o trabalhador que era livre e dispunha de sua força de trabalho, no sistema capitalista teve que dispor dela, já que não possuía outra coisa para vender. Se o escravo tinha assegurado a sua alimentação, o assalariado nem ao menos pode comprar a sua, a não ser que o capitalista necessite do seu trabalho para transformar dinheiro em capital, conforme aponta Marx (2013, p. 314).

Para transformar dinheiro em capital, o possuidor de dinheiro tem, portanto, de encontrar no mercado de mercadorias o trabalhador livre, e livre em dois sentidos: de ser uma pessoa livre, que dispõe de sua força de trabalho como sua mercadoria, e de, por outro lado, ser alguém que não tem outra mercadoria para vender, livre e solto, carecendo absolutamente de todas as coisas necessárias à realização de sua força de trabalho. (p. 315-316)

Assim, o trabalhador ao depender do capitalista para manutenção da sua sobrevivência e necessidades básicas, foi condenado ao papel de assalariado por toda sua existência.

Ao longo da sua trajetória o sistema capitalista passou por vários estágios, mas conforme pontua Netto (1996) foi no século XIX que passou por profundas transformações, nesse sentido, segundo o autor:

[...] está consensualmente aceite que o capitalismo, no ultimo quartel do século XIX, experimenta profundas modificações no seu ordenamento e na sua dinâmica econômicos, com incidências necessárias na estrutura social e nas instancias políticas das sociedades nacionais que envolvia. Trata-se do período histórico em que ao capitalismo concorrencial sucede o capitalismo dos monopólios, articulando o fenômeno global [...] é também consensual que "o período do imperialismo 'clássico' [situa-se] entre 1890 e 1940" o capitalismo monopolista recoloca, em patamar mais alto, o sistema totalizante de contradições que confere à ordem burguesa os seus traços basilares de exploração, alienação e transitoriedade histórica, todos eles desvelados pela crítica marxiana. (NETTO, 1996, p. 15)

A era dos monopólios de acordo com Netto (1996) altera toda a dinâmica da sociedade burguesa, por um lado potencializando as contradições já existentes no capitalismo concorrencial e por outro lado trazendo novas contradições e antagonismos, focando na exploração da força do trabalho e maximização dos lucros.

O sistema capitalista vigente tem provocado profundas transformações na sociedade contemporânea nas últimas décadas segundo descreve Antunes (1999), manifestas tanto nas formas de materialidade quanto na forma de subjetividade. A partir do início da década de 1970, o capital se subjugou em resposta à sua própria crise a um processo de reorganização produtiva 
em escala global, tendo repercutido não só no sistema econômico, mas também no plano ideológico e político de dominação. Suas expressões mais radicais colocam-se expressas no neoliberalismo, na reforma do Estado, na desregulamentação dos direitos trabalhistas, na desmontagem do setor produtivo estatal e no processo de reestruturação da produção e do trabalho.

Já na década de 1980 Antunes (2000) afirma que grandes transformações ocorreram no mundo do trabalho nos países capitalistas, impactando fortemente na classe trabalhadora repercutindo, nas mais diversas categorias profissionais, dentre as quais no Serviço Social, atingindo tanto a materialidade quanto a subjetividade da classe trabalhadora, alterando a sua forma de ser. Essas mudanças foram oriundas da inovação dos meios de produção, a tecnologia se inseriu nas relações de trabalho e produção de capital, é uma época de grandes experimentos, o fordismo e o taylorismo já não são únicos e mesclam-se a outros processos produtivos. Assim, novos processos de trabalho surgem, a produção em série e em massa são substituídos pela flexibilização da produção, pela especialização flexível, novos padrões de produtividade e formas de adequação à lógica do capital.

Antunes (1999) discorre que entre as respostas apresentadas as crises vivenciadas pelo Capital estão o neoliberalismo e a reestruturação produtiva da era da acumulação flexível, acarretando profundas mudanças no mundo do trabalho, "tais como desemprego estrutural, um crescente contingente de trabalhadores em condições precarizadas, além de uma degradação que se amplia na relação metabólica entre o homem e a natureza" [...] (ANTUNES, 1999, p. $15)$.

Ainda na lógica de Antunes (1999) o sistema vigente vem convertendo a concorrência e a busca da produtividade em um processo destrutivo que tem acarretado em mutações e metamorfoses no mundo do trabalho, gerando a precarização das formas de trabalho e o aumento do exército industrial de reserva ${ }^{4}$, pois para que o processo de acumulação ampliada se restaure é necessário que haja grande número de trabalhadores disponíveis e dispostos a ser prontamente absorvida, uma grande massa de trabalhadores que se dispõe a jornadas excessivas de trabalho, pois caso o trabalhador não se submeta as condições impostas prontamente será substituído. Assim, diante desse cenário surge o trabalhador polivalente, multifuncional, aquele

\footnotetext{
4 "Exército Industrial de Reserva é um produto da acumulação, é, também, uma das condições para que esta se efetive. A existência de uma superpopulação trabalhadora disponível, independe dos limites reais de crescimento da população, é condição fundamental para a vida do próprio regime do capital". (IAMAMOTO, 2007, p.59)
} 
que exerce diversas tarefas, deixando de ser um trabalhador especializado, desenvolvendo funções para além daquelas que dizem respeito as suas atribuições.

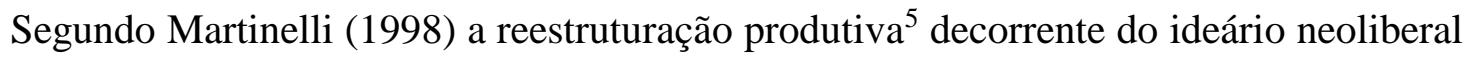
tem mudado o significado do trabalho, a situação se agrava ao compreender que o trabalho está sendo depredado, incorrendo nas desumanas: automação e com a flexibilização das leis trabalhistas. Tal processo ocorre conforme a necessidade do capitalista, que, devido ao exército industrial de reserva, tem à sua disposição a instabilidade dos empregos, tornando o ser social num objeto obsoleto. Instaura-se, assim, a intranqüilidade, pois o trabalhador perde a dignidade. Os indivíduos que ainda têm seus trabalhos são submetidos a regras desumanas com salários baixos, e a classe operária perde a "qualidade de vida".

Com a exploração e a submissão do trabalhador, o ser social perde seus valores e o desejo de lutar por melhores condições de trabalho e seguridade, há a intensificação da exploração do trabalho infantil e da mulher, que ganham menos que o homem, convenientemente o exército industrial de reserva contribui para a flexibilização e precarização do trabalho, concomitantemente a isso aumenta exponencialmente o acúmulo de riqueza, com a mesma proporção aumenta a pauperização, exclusão social e a miserabilidade da classe trabalhadora.

A ideologia neoliberal responsável pela fragilidade do mundo do trabalho, fragmenta o acesso aos direitos sociais, desse modo, pulverizando a democracia e a cidadania, ambas as categorias fundantes, que se metamorfoseiam.

Diante de todas as transformações ocorridas no mundo do trabalho, principalmente nas últimas décadas, a classe trabalhadora no Brasil sofreu um dos maiores ataques, que fere na alma a classe trabalhadora, ataque esse que ocorreu com a aprovação da reforma trabalhista, a Lei $n^{\circ}$ 13.467/2017 que altera a Consolidação das Leis Trabalhistas (CLT) regulamentando novas formas de trabalho, como acirramento do trabalho autônomo, trabalho intermitente, trabalho terceirizado, jornada parcial, aumento da jornada de trabalho, parcelamento das férias em até três vezes, novas formas de contrato, regulamentação do trabalho temporário, negociação direto entre empregado e patrão, dentre outros, desconsiderando os direitos e garantias assegurados constitucionalmente, fruto da luta da classe trabalhadora, retirando a já tão frágil rede de proteção social existente.

\footnotetext{
5 "Reestruturação produtiva são as mudanças causadas nas condições e relações no mundo do trabalho, gerando novas formas de gestão do trabalho no qual a luta social do trabalhador e enfraquecida". (PERUZZO, 2002)
} 
As consequências da reforma que incluem a desconstrução de direitos, a desestruturação do mercado de trabalho, a fragilização dos sindicatos, por meio da alteração na forma de contribuição que passa a ser facultativa, estratégia de enfraquecimento e desmobilização dos sindicatos, ampliando as situações de vulnerabilidade, a deterioração das condições de vida e de saúde do trabalhador, o comprometimento do financiamento da seguridade social e a ampliação da desigualdade e da exclusão social, acirrando ainda mais as expressões da questão social.

É diante deste cenário que o assistente social, enquanto trabalhador assalariado se insere e intervém.

\section{O ASSISTENTE SOCIAL ENQUANTO TRABALHADOR ASSALARIADO}

A partir das leituras realizadas sobre a origem do Serviço Social foi possível aferir que os diversos autores que discorrem sobre o assunto pontuam que a gênese da profissão está intrinsecamente ligada ao sistema capitalista, tendo espaço no mundo do trabalho mais precisamente na transição do capitalismo concorrencial para o capitalismo monopolista, período este marcado pelo acirramento das expressões da questão social ${ }^{6}$ e a organização da classe trabalhadora que passa a pressionar o empresariado e o Estado exigindo melhores condições de vida, conforme Iamamoto aponta:

O Estado passa a intervir diretamente nas relações entre o empresariado e a classe trabalhadora, estabelecendo não só uma regulamentação jurídica do mercado de trabalho, através da legislação social e trabalhista específicas, mas gerindo a organização e prestação dos serviços sociais, como um novo tipo de enfrentamento da questão social (2000, p. 77)

Deste modo, à medida que a classe trabalhadora se mobiliza exigindo respostas que vão além da caridade ou repressão, passando a ser uma ameaça à manutenção da ordem burguesa, o Estado passa a intervir frente às expressões da questão social por meio das políticas sociais, se tornando mantenedor da conservação da ordem burguesa.

Conforme relata Netto (1996, p. 25).

\footnotetext{
6 “A questão social não é senão as expressões do processo de formação e desenvolvimento da classe operária e de seu ingresso no cenário político da sociedade, exigindo seu reconhecimento como classe por parte do empresariado e do Estado. É a manifestação, no cotidiano da vida social, da contradição entre o proletariado e a burguesia"[...] (IAMAMOTO; CARVALHO, 2000, p. 77)
} 
[...] O capitalismo monopolista, pelas suas dinâmicas e contradições, cria condições tais que o Estado por ele capturado, ao buscar legitimação política através do jogo democrático, é permeável a demandas das classes subalternas, que podem fazer incidir nele seus interesses e suas reivindicações imediatas. E que este processo é todo ele tensionado, não só pelas exigências da ordem monopólica, mas pelos conflitos que esta faz dimanar em toda escala societária.

As políticas sociais na era dos monopólios é uma necessidade que viabiliza a manutenção desse sistema, assim, o Estado passa a administrar as políticas sociais indo da formulação, até a execução destas, fortalecendo e apoiando tal sistema, de modo que se torna o seu principal legitimador ao intervir nas tensões e conflitos derivados da contradição Capital/trabalho.

Neste sentido, na perspectiva de garantir a reprodução social das condições que possibilitam a manutenção da ordem burguesa por meio das políticas sociais, o Estado necessita de profissionais para trabalhar na execução destas políticas, sendo assim, se abre espaço na divisão sócio técnica do trabalho para o Serviço Social conforme salienta (NETTO, 1996 p. 70):

O processo pelo qual a ordem monopólica instaura o espaço determinado que na divisão social (e técnica) do trabalho a ela pertinente, propicia a profissionalização do Serviço Social tem sua base nas modalidades através das quais o Estado burguês se enfrenta com "a questão social", tipificadas nas políticas sociais [...]

Neste contexto está posto o mercado de trabalho para os assistentes sociais, atuando na execução das políticas sociais do Estado burguês, como uma profissão que contribuirá para a reprodução das relações sociais, baseado em uma postura conservadora e com o discurso voltado para a ideologia burguesa, a moral e aos bons costumes.

No Brasil, de acordo com Craveiro (2017) o surgimento do Serviço Social se dá a partir de 1930, estando relacionado ao amadurecimento do sistema capitalista no país, marcados pelo aumento da industrialização e processo de urbanização que trouxe como conseqüências o acirramento da exploração da força de trabalho e pauperização, ocasionando no aumento das mazelas da questão social. Deste modo, assim como ocorreu na Europa e Estados Unidos a classe proletária se organizou em prol de melhores condições de vida, colocando em risco a hegemonia da ordem burguesa. Assim, como forma de mediação e controle da classe trabalhadora, o Estado, a serviço da classe dominante se utilizou de políticas sociais especificas para apaziguar as manifestações e garantir a manutenção e expansão do sistema capitalista.

Nas palavras de Craveiro (2017) concomitante ao contexto vivenciado pelo Estado a Igreja Católica passava por um processo de perda de fiéis em decorrência dos escândalos 
relacionados à Igreja, e também devido ao aumento do protestantismo no Brasil. De um lado temos o Estado que está passando por mudanças políticas e de outro lado a Igreja Católica que quer resgatar seus fieis e garantir sua hegemonia, assim, Estado e Igreja se aliam, e é nesse cenário, marcado pela ideologia da Igreja Católica que o Serviço Social no Brasil se constitui.

Segundo discorre Iamamoto e Carvalho (2000) os primeiros profissionais assistentes sociais tinham uma prática profissional marcada pelo conservadorismo e o discurso pautado na moral e bons costumes da época. No entanto Craveiro (2017, p. 12) aponta que:

Com as transformações da própria sociedade que irá impactar na profissão do Serviço Social e com as modificações ocorridas na própria profissão, esta veio se desenvolvendo e ganhando novas características e formas de atuação, sendo que a atuação do Serviço Social na atualidade não segue o mesmo direcionamento realizado pelos primeiros assistentes sociais. [...] em cada contexto lugar, e contexto histórico, a profissão do Serviço Social ganhará novas formatações e características próprias.

Se nas protoformas da profissão, o Serviço Social era tido como uma profissão marcada pela ideologia doutrinadora da Igreja Católica, representado por jovens mulheres católicas da classe dominante, com ilibada formação moral, sentimentos nobres, senso de servir aos menos favorecidos e com ações voltadas para a ajuda e caridade, ao longo dos anos a profissão no Brasil foi passando por processos de amadurecimento profissional e os assistentes sociais começaram a questionar sua prática profissional frente às expressões da questão social. Os modelos utilizados pelo Serviço Social, importados, não condiziam mais com a realidade apresentada, diante da conjuntura vivenciada pelos profissionais assistentes sociais durante a ditadura militar surgiu o Movimento de Reconceituação ${ }^{7}$ que foi o marco histórico para a profissão, pois uma nova forma de atuar foi pensada e desvelou segundo Netto (2006) dois traços marcantes, sendo que o primeiro traço se deu a partir da aproximação com a raiz marxiana, embora nesse primeiro momento tenha ocorrido por meio da teoria do marxismo vulgar, que provocou inúmeros equívocos, ainda assim, essa aproximação eliminou a estranheza referente à teoria marxiana e proporcionou um estudo mais aprofundado nos anos posteriores. O segundo traço se refere à aproximação entre os profissionais da América Latina, que defenderam uma nova forma de identidade para o Serviço Social, que atendesse os problemas específicos dos países da América Latina, já que o Serviço Social com a ideologia norte-americana não atendia nossas idiossincrasias.

\footnotetext{
${ }^{7}$ Movimento de Reconceituação é um termo usado por NETTO, para designar autocrítica do Serviço Social.
} 
A profissão conforme apontamentos de Iamamoto (2001) desde a década de 1980 se afirma como uma especialização do trabalho, inscrita na divisão sócio técnica do trabalho, regulamentado como uma profissão liberal, tendo o Estado como seu maior empregador, detendo uma relativa autonomia profissional em suas intervenções, autonomia relativa devido ao fato que ao vender sua força de trabalho em troca de um salário, os empregadores são detentores dos meios e instrumentos necessários para o desenvolvimento da prática profissional, dependemos dos recursos disponibilizados pelos empregadores.

Nessa perspectiva Iamamoto (2001) aponta que o assistente social enquanto trabalhador assalariado que vende sua força de trabalho para empregadores estatais ou privados, entrega seu valor de uso, realizando intervenções cotidianas por meio do processo de trabalho, esses processos de trabalho variam de acordo com o espaço ocupacional onde está inserido o profissional. Cabe ressaltar que segundo Marx (2013) o processo de trabalho é composto por três elementos basilares: o próprio trabalho, a matéria prima e os instrumentos de trabalho.

Desta forma, conforme destaca Craveiro (2017), no que se refere ao primeiro elemento do processo de trabalho, o próprio trabalho, trabalho vivo, é ele que impulsiona a ação profissional do Assistente Social em torno do seu objeto de trabalho, as expressões da questão social.

Com a intencionalidade de responder às demandas apresentadas pela questão social, o assistente social no seu cotidiano, se apropria da capacidade intelectual para realizar o seu fazer profissional, e é no decorrer desse fazer profissional e dos estudos e acúmulos de saberes que o assistente social articula estratégias para atingir seus objetivos e transformar uma determinada realidade social, a ação desse profissional é prenhe de instrumentalidade tanto nas nossas intervenções micro e macroscópicas, logo, a instrumentalidade ao mesmo tempo em que é condição fulcral para o trabalho do assistente social, também se materializa como categoria peculiar que imprimindo/formatando o resultado do trabalho desse profissional. Enfim o fazer profissional por si só é uma instrumentalidade, pois por meio das mediações, intervém e modifica as relações sociais dos usuários.

A instrumentalidade do Serviço Social coloca-se não apenas como a dimensão constituinte e constitutiva da profissão mais desenvolvida, referenciada pela prática social e histórica dos sujeitos que a realizam, mas, sobretudo, como campo de mediação no qual os padrões de racionalidade e as ações instrumentais se processam. Se isso é verdade, há que se discernir entre instrumentalidade, enquanto conduto de passagem das racionalidades; ações instrumentais, enquanto atividades finalísticas; e grau de abrangência das modalidades da razão que iluminam as ações profissionais. (GUERRA, 1999, p. 38). 
Assim sendo, a instrumentalidade para o assistente social é a dimensão fulcral, é a base de apoio para um fazer profissional que desvele a essência e que possibilite a transformação do que está posto.

Iamamoto (2001) observa que o principal instrumento de trabalho do assistente social é a linguagem, por meio dela se abre possibilidades ao profissional em seus mais diversos espaços sócio ocupacionais de desenvolver uma ação sócio educativa, possibilitando aos usuários se apropriarem de saberes relacionados a seus direitos.

Nesse sentido, assistente social enquanto trabalhador assalariado terá de se utilizar da sua intelectualidade, criticidade, instrumentalidade e capacidade de proposição para enfrentar os desafios contemporâneos que veremos no próximo tópico.

\section{DESAFIOS PRESENTES NO COTIDIANO PROFISSIONAL DO ASSISTENTE SOCIAL NA CONTEMPORANEIDADE}

Conforme pontua Iamamoto (2001, p. 17) “o momento em que vivemos é um momento pleno de desafios. Mais do que nunca é preciso ter coragem, é preciso ter esperanças para enfrentar o presente. É preciso resistir e sonhar [...] alimentar os sonhos", deste modo, se o tempo em que vivemos é permeado por desafios, é preciso coragem e resistência na perspectiva da concretização de tempos mais justos e solidários para a classe trabalhadora, pois na atualidade os profissionais assistentes sociais são constantemente desafiados a dar respostas que venham de encontro às novas bases de produção da questão social. São tempos sombrios, tempos de crise, de desemprego, de precarização do trabalho, de retirada de direitos, são tempos difíceis para todos aqueles que dependem do trabalho para garantir sua subsistência e também são tempos difíceis para aqueles que atuam em defesa da classe trabalhadora.

Destarte, estando a profissão do Serviço Social diretamente ligado à dinâmica da sociedade capitalista, se insere hoje nesses tempos, marcado por profundas transformações na sociedade e no modo de produção, decorrentes do ideário neoliberal, que avança na perspectiva de retirada dos direitos conquistados, fruto da mobilização e luta de diversos grupos e movimentos sociais. As políticas públicas passam a sofrer desmontes dentro dessa lógica amparada nos princípios da privatização e flexibilização, onde se prega um Estado mínimo para o social e máximo para o capital.

A ideologia neoliberalista, a qual fragiliza o mundo do trabalho, também é responsável pela fragmentação dos direitos sociais, que pulveriza a democracia e a cidadania categorias fundantes, que se metamorfoseiam. Ser cidadão no sistema vigente é ter poder de consumo, 
assim, perde-se o significado de direitos sociais que já não são entendidos como dantes, com caráter jurídico e universal. Nesta conjuntura política, social e econômica, as políticas sociais se tornam inoperantes e o assistente social trava cotidianamente o enfrentamento frente às diversidades na luta pela justiça social.

Compreende-se a partir dos apontamentos de Craveiro (2017) que a profissão assistente social, e os espaços sócio ocupacionais em que este profissional se insere, está intrinsecamente ligado à dinâmica da sociedade capitalista, e sofre diretamente os impactos advindos das transformações políticas, econômicas e sociais que vem ocorrendo nas últimas décadas. Tais impactos ganharam proporções ainda maiores a partir do processo de impeachment da presidenta Dilma Rousseff, ocorrido no ano de 2016, pois o que vemos posterior a esse processo é o ataque massivo as políticas públicas, algumas já materializadas, como a aprovação da Lei da reforma trabalhista Lei $n^{\circ} 13.467 / 2017$ que altera a Consolidação das Leis Trabalhistas (CLT) e o Projeto de Emenda Constitucional (PEC) 55 que congela os gastos públicos com saúde, educação e assistência social por 20 anos, atingindo principalmente a parcela mais pobre da população.

Para legitimar tais reformas, o governo conta com a ajuda da mídia de massa, que repetidamente propaga a ideia de supostos déficits, sendo necessário o enxugamento da dos gastos públicos. Assim, com manipulação das informações, provocando a naturalização da ideia de que tais reformas são necessárias para garantir o futuro acesso da população a políticas públicas.

Portanto, diante desse cenário o assistente social necessita se qualificar intelectualmente e constantemente, respeitando o projeto ético-político, e isso requer um acúmulo teóricometodológico para organizar a ação profissional, criando estratégias para o trabalho cotidiano, pois o profissional se vê na contradição em responder as demandas do empregador e também as demandas da classe trabalhadora, tem que propor sugestões/soluções aos seus empregadores, assim como, aderindo a um projeto societário em defesa dos trabalhadores.

Outro fator que mobiliza a ação profissional são as necessidades dos usuários. O assistente social não tem um modelo a seguir, ou seja, não há receita de como atuar, cada ser social tem a sua historicidade e necessidade, por isso a necessidade do profissional ter um aporte teórico-metodológico suficiente para o entendimento de cada particularidade da realidade além da aparência que necessita de um segundo momento de ação.

Desta forma, podem-se vislumbrar os limites e as possibilidades, oportunizando traçar estratégias de enfrentamento em defesa dos direitos sociais e da classe oprimida. Como enfrentamento, esses profissionais intelectualizados se posicionam a favor da classe 
trabalhadora intervindo por meio de lutas e reivindicações, criando estratégias para concretizar os direitos sociais do ser social.

Segundo Netto (2006), contrariando este projeto profissional, alguns profissionais aderem inconscientemente às imposições neoliberais com o viés conservador travestidos de novas molduras teórico-práticos.

Diante das dificuldades postas aos profissionais assistentes sociais na atualidade, Iamamoto (2001) observa que entre os maiores desafios está a capacidade dos profissionais assistentes sociais em atuar diante dessa realidade, desvelando-a e construindo propostas de trabalho criativas que dão conta de garantir e efetivar acesso a direitos. Ou seja, o profissional não deve ser um mero executor, mas sim um profissional propositivo, que vá além das atividades burocráticas e rotineiras, não se limitando ao cumprimento de tarefas prédeterminadas que reduza o exercício profissional a mero emprego. $\mathrm{O}$ exercício da profissão requer mais que isso, requer um profissional com competência para propor, negociar com os empregadores seus projetos, defender seu campo sócio ocupacional, suas qualificações e funções, um sujeito profissional que visa apreender a realidade além daquilo que está aparentemente dado, para identificar possibilidades, mas também identificar as contradições presentes no cotidiano do exercício profissional. "As possibilidades estão dadas na realidade, mas não automaticamente transformadas em alternativas profissionais. Cabe aos profissionais apropriarem-se dessas possibilidades [...] transformando-as em projetos e frentes de trabalhos" (IAMAMOTO, 2000, p. 2)

\section{CONSIDERAÇOES FINAIS}

A construção do presente estudo possibilitou o aprofundamento da reflexão sobre as mudanças ocorridas nas últimas décadas no interior do mundo do trabalho, desse modo, partimos do pressuposto do reconhecimento do trabalho enquanto categoria fundante do ser social, que ao longo de seu processo histórico sofreu mutações, sendo que o trabalhador que a princípio transformava a natureza para garantir suas necessidades básicas, na sociedade capitalista, passa a ter que vender sua força de trabalho para garantir sua subsistência.

Inserido na dinâmica da sociedade capitalista como uma profissão que contribui para a reprodução das relações sociais, o Serviço Social se insere na divisão sócio técnica do trabalho, regulamentado como uma profissão liberal, detentor de uma relativa autonomia, reconhece-se o assistente social enquanto trabalhador assalariado que vende sua força de trabalho em troca de um salário, assim, os empregadores são detentores da sua força de trabalho e o exercício 
profissional muitas vezes é limitado pelas imposições dos empregadores, pois os profissionais nem sempre dispõe dos meios necessários para efetivação do seu exercício profissional.

Contemporaneamente vivemos tempos sombrios, de desregulamentação, flexibilização, precarização do trabalho, retirada de direitos, enxugamento das políticas públicas, onde o assistente social se insere enquanto trabalhador assalariado que também é explorado e sofre com as mudanças ocorridas nas últimas décadas decorrentes do sistema capitalista vigente, tendo que intervir frente a essa realidade tendo como condições de trabalho a precariedade e o desmonte das políticas públicas.

Desta forma, o estudo buscou ampliar o debate crítico sobre os desafios contemporâneos do assistente social, mostrando que mesmo vivendo em um momento pleno de desafios, também há possibilidades de se buscar uma sociedade mais justa e igualitária, pois somos profissionais forjados na luta. Os assistentes sociais “apesar do seu pouco prestígio social e dos baixos salários, formam uma categoria que tem ousado sonhar, que tem ousado ter firmeza na luta, que tem ousado resistir aos obstáculos, porque aposta na história, construindo o futuro, no presente" (IAMAMOTO, 2001, p. 80).

\section{Referências}

ANTUNES, R. Adeus ao trabalho? Ensaio sobre as metamorfoses e a centralidade do mundo do trabalho. Campinas: Cortez - 10 $0^{\mathrm{a}} \mathrm{Ed} .2000$.

ANTUNES, R. Os sentidos do trabalho: Ensaio sobre a afirmação e a negação do trabalho. São Paulo: Boitempo. $7^{\mathrm{a}}$ reimpressão, 1999.

ANTUNES, R. SILVA, M. A. M. O avesso do trabalho. $1^{\text {a }}$. Ed. - São Paulo: Expressão Cultural, 2004.

CRAVEIRO, A. V. Trajetória histórica da profissão do Serviço Social. 2017.

GUERRA, Y. A instrumentalidade do Serviço Social. São Paulo, Cortez. 1999. 
IAMAMOTO, M. V; CARVALHO, R. Relações sociais e Serviço Social no Brasil: Esboço de uma interpretação histórico-metodológica. 20. Ed. - São Paulo: Cortez, 2000.

IAMAMOTO, M. V. O Serviço Social na contemporaneidade: trabalho e formação profissional. - São Paulo: Cortez, 4a . Ed., 2001.

IAMAMOTO \& MOTA ... [et al], (orgs), Ana Elizabete, Marilda Vilella. As dimensões éticopolíticas e teórico-metodológicas no Serviço Social contemporâneo. - $2^{\mathrm{a}}$. Ed. - São Paulo: Cortez, 2007.

PERUZZO, J F. Reestruturação produtiva e sistema de proteção social. In Revista Virtual Textos e Contextos. PUCRS. Porto Alegre: 2002

MARTINELLI, M. L. O ensino teórico-prático do serviço-social: demandas e alternativas. In: Serviço Social \& Sociedade nº 44. São Paulo: Cortez, 1994.

MARTINELLI, M. L. O Serviço Social na transição para o próximo milênio: desafios e perspectivas. In: Serviço Social \& Sociedade nº. 57. São Paulo: Cortez, 1998.

MARX, K. O Capital. Crítica da economia política. Livro I. O processo de produção do capital. Boitempo Editorial, 2013.

MARX, K. O capital. Edição Condensada por Gabriel Deville. EDIPRO. $3^{\text {a }}$ Edição, $3^{\text {a }}$ Reimp. Bauru - SP. 2016.

MARX E ENGELS, K e F. O Manifesto comunista. Rio de Janeiro: Paz e Terra, 1998.

NETTO, J. P. Capitalismo monopolista e Serviço Social. 2a . Ed. - São Paulo: Cortez, 1996.

NETTO, J. P. Ditadura e Serviço Social: Uma análise do Serviço Social no Brasil pós-64. 9a. Ed. - São Paulo: Cortez, 2006.

NETTO, J. P. Transformações societárias e Serviço Social: notas para uma análise prospectiva da profissão no Brasil. In: Revista Serviço Social \& Sociedade. Nº. 50, 1996.

PASSOS, R. G.Trabalho, cuidado e sociabilidade: contribuições marxianas para o debate contemporâneo. In: Revista Serviço Social \& Sociedade. No. 126, São Paulo, 2016. 